\title{
AUMENTO DA VIDA ÚTIL PÓS COLHEITA DE PEDÚNCULOS DE CAJUEIRO ANÃO PRECOCE PELA REDUÇÃO DA TEMPERATURA DE ARMAZENAMENTO
}

\author{
Increasing shelf life of early dwarf cashew tree peduncle through reduction \\ of storage temperature
}

\author{
Carlos Farley Herbster Moura' ${ }^{1}$, Raimundo Wilane de Figueiredo ${ }^{2}$, Ricardo Elesbão Alves ${ }^{3}$, \\ Ebenézer de Oliveira Silva ${ }^{4}$, Paolo Germanno Lima de Araújo ${ }^{5}$, Vlayrton Tomé Maciel ${ }^{6}$
}

\begin{abstract}
RESUMO
Conduziu-se este estudo, realizado no Laboratório de Fisiologia e Tecnologia Pós-Colheita da Embrapa Agroindústria Tropical em Fortaleza (CE), com o objetivo de aumentar o tempo de conservação pós-colheita de pedúnculos dos clones CCP 76 e END 183 de cajueiro anão precoce por meio da redução da temperatura de armazenamento. Foi adotado um fatorial em delineamento inteiramente casualizado, cujos fatores foram os clones e o tempo de armazenamento $(0,5,10,15,20,25$ e 30 dias), avaliados em três repetições. Os frutos, colhidos manualmente, no início da manhã, no Município de Beberibe, Ceará, foram acondicionados em caixas plásticas ainda no campo e transportados para o laboratório onde, acondicionados em bandejas de isopor, foram armazenados a $3,4 \pm 0,6^{\circ} \mathrm{C}$ e umidade relativa de $85 \pm 11 \%$, sob atmosfera modificada. Os parâmetros avaliados foram perda de massa, aparência, cor da película, firmeza da polpa, sólidos solúveis totais, pH, acidez total titulável, SST/ATT, ácido ascórbico, açúcares solúveis totais, antocianinas totais e fenólicos. Os resultados mostraram que os pedúnculos do clone CCP 76 têm vida útil pós-colheita de 18 dias, enquanto o END 183, de 28 dias, ambos com reduzida perda de massa, firmeza e antocianinas totais.
\end{abstract}

Termos para Indexação: Anacardium occidentale L., qualidade, atmosfera modificada.

\section{ABSTRACT}

This work aimed to increase, through the reduction storage temperature, the post-harvest conservation time of the early dwarf cashew tree peduncle of clones CCP 76 and END 183. It was carried out in the Postharvest Physiology and Technology Laboratory of the Embrapa Agroindústria Tropical in Fortaleza (State of Ceará, Brazil) using a factorial scheme in a randomized design with three replications of the factors (clones and storage duration: $0,5,10,15,20,25$ and 30 days). The fruits evaluated were manually harvested in a farm located in the Municipality of Beberibe, State of Ceará, transported in plastic containers to the Laboratory and stored in extruded polystyrene trays at the temperature of $3,4 \pm 0,6^{\circ} \mathrm{C}$ and relative humidity $85 \pm 11 \%$ under modified atmosphere. The parameters evaluated were weight loss; appearance; peel color; pulp firmness; total soluble solids (TSS); pH; total titratable acidity (TTA); TSS/TTA ratio; ascorbic acid; total soluble sugars; anthocyanins and phenolics. The analyses showed that the shelf life of the CCP 76 peduncle clone is 18 days while that of the END 183 clone is of 28 days, both with slight loss of mass, firmness and total anthocyanins.

Index Terms: Anacardium occidentale L., quality, modified atmosphere.

(Recebido em 4 de setembro de 2007 e aprovado em 19 de outubro de 2009)

\section{INTRODUÇÃO}

Grandes segmentos populacionais do nordeste brasileiro têm no caju importante fonte de recursos, sendo inclusive, para muitos municípios, a principal cultura geradora de divisas (Menezes et al., 1992). Para essa região, sua importância é ainda maior porque os empregos do campo são gerados na entressafra das culturas tradicionais como milho, feijão e algodão, reduzindo o êxodo rural (Oliveira, 2002).

Uma das grandes dificuldades enfrentadas pelos produtores, principalmente os que visam o consumo in natura do caju, é sua vida útil pós-colheita extremamente curta, decorrente da delicada estrutura do pedúnculo associado à rápida perda de firmeza, comprometendo sobremaneira a comercialização desse produto. Nos dias de hoje, com a tecnologia atualmente recomendada, a colheita deve ser feita nas horas de temperaturas mais amenas e os cajus devem ser acondicionados em uma única camada, nas caixas plásticas de colheita ( 47 x 30,5 x 12cm), as quais são revestidas internamente por uma camada de espuma de aproximadamente $1 \mathrm{~cm}$ de espessura, para não danificar o pedúnculo. Após a seleção efetuada no 'packing house',

1Embrapa Agroindústria Tropical - Rua Dra. Sara Mesquita - 2270 - Bairro Pici - 60511-110 - Fortaleza,CE - farley@cnpat.embrapa.br 'Universidade Federal do Ceará/DTA - Fortaleza, CE

${ }^{3}$ Embrapa Agroindústria Tropical - Fortaleza, CE

${ }^{4}$ Embrapa Agroindústria Tropical - Fortaleza, CE

Universidade Federal do Ceará/DTA - Fortaleza, CE

Universidade Federal do Ceará - Departamento de Fitotecnia - Fortaleza, CE

Ciênc. agrotec., Lavras, v. 34, n. 1, p. 140-145, jan./fev., 2010 
os cajus devem ser colocados em bandejas de isopor embaladas com filme de PVC e armazenadas sob refrigeração $\left(5^{\circ} \mathrm{C}\right)$, sendo possível a comercialização desses pedúnculos a grandes distâncias (Filgueiras et al., 1999).

A conservação pós-colheita do pedúnculo do cajueiro à temperatura ambiente não ultrapassa $48 \mathrm{~h}$, em razão da sua extrema susceptibilidade ao ataque de microrganismos fitopatogênicos, responsáveis pelo estabelecimento de um rápido processo fermentativo (Figueiredo, 2000). Desta forma, torna-se fundamental o desenvolvimento de métodos de conservação que prolonguem a vida útil dos pedúnculos, sem que sua estrutura física original e composição química sejam alteradas e, consequentemente, permitam a oferta destes e de seus derivados durante todo o ano. Levando-se em conta essa tendência de novos métodos de conservação, Souza et al. (2009) em trabalho realizado com irradiação gama em pedúnculos do cajueiro, encontraram um aumento da firmeza na concentração de $0,5 \mathrm{kGy}$ com o decorrer do tempo de armazenamento, aumentando com isso a vida útil desses pedúnculos.

Conduziu-se este trabalho, com o objetivo de avaliar a conservação pós colheita de pedúnculos alaranjados dos clones de cajueiro anão precoce CCP 76 e END 183 armazenados a $3^{\circ} \mathrm{C}$ em associação com atmosfera modificada.

\section{MATERIAL E MÉTODOS}

Cajus obtidos no Município de Beberibe, Ceará, dos clones CCP 76 e END 183 (alaranjados), foram colhidos, manualmente, nas horas mais frescas do dia (início da manhã) e colocados, após a colheita, sob a copa do próprio cajueiro. Esses cajus foram acondicionados em uma camada de frutos em caixas plásticas, cujo fundo foi protegido com revestimento interno de espuma de aproximadamente $1 \mathrm{~cm}$ de espessura, com o objetivo de proteger os pedúnculos. Logo após, foram transportados para o Laboratório de Fisiologia e Tecnologia Pós-Colheita da Embrapa Agroindústria Tropical localizado em Fortaleza, Ceará, onde foram acondicionados em bandejas de isopor.

As bandejas, contendo três cajus cada, foram revestidas com uma camada de filme de PVC $(12 \mathrm{~m})$ e pesadas com a finalidade de se determinar a perda de massa ao longo do armazenamento. Em seguida, foram armazenados em câmara fria a $3,4 \pm 0,6^{\circ} \mathrm{C}$ e umidade relativa de $85 \pm 11 \%$. As análises físicas, físico-químicas e químicas foram realizadas no tempo zero e a cada cinco dias, por um período de 30 dias, constando de: perda de massa expressa em porcentagem; aparência usando uma escala com notas, variando entre 0 e 4 , onde nota 0 indica pedúnculo com aparência boa, resistente ao choque mecânico, isento de enrugamento, cheiro agradável; e nota 4 , liberação espontânea do suco, presença de fungos, cheiro desagradável, imprestável para o consumo (Figueiredo, 2000), sendo os pedúnculos considerados aptos para o consumo até a nota 2 (descoloração em aproximadamente metade do pedúnculo); cor da película (Luminosidade, Cromaticidade e ${ }^{\circ} \mathrm{Hue}$ ) por meio do uso do Colorímetro Minolta, modelo CR-300, determinada pela média de duas leituras de acordo com McGuire (1992); firmeza da polpa, usando-se texturômetro eletrônico de bancada (Stable Micro Systems TA-XT2 i) equipado com plunger de $6 \mathrm{~mm}$ de diâmetro; teor de sólidos solúveis totais (SST) expresso em ${ }^{\circ}$ Brix (AOAC, 1992); pH (AOAC, 1992); acidez total titulável (ATT) expressa em \% e de acordo com Instituto Adolfo Lutz (1985); SST/ATT obtida por meio do quociente entre os resultados obtidos; ácido ascórbico de acordo com Strohecker \& Henning (1967) e expressos em mg/100g; açúcares solúveis totais (AST) (\%) de acordo com Yemn \& Willis (1954); antocianinas totais $(\mathrm{mg} / 100 \mathrm{~g})$ doseadas, segundo Francis (1982) e fenólicos dímeros, oligoméricos e poliméricos, expressos em percentagem (Reicher et al., 1981).

$\mathrm{O}$ experimento foi conduzido em ensaio fatorial com delineamento inteiramente casualizado e dois fatores, clone $\mathrm{x}$ tempo (2x7) (Banzatto \& Kronka, 1992). Para as avaliações foram utilizadas três repetições.

\section{RESULTADOS E DISCUSSÃO}

Os pedúnculos apresentaram perdas de massa crescentes no decorrer do armazenamento, mesmo com o uso da atmosfera modificada, atingindo valores de 1,3\%, ao final do armazenamento (Figura 1A), não se observando nenhum sintoma de murchamento no período.

Apesar de se ter encontrado uma perda de massa superior (1,3\%) à encontrada por Menezes et al. (1992) $(0,8 \%)$ e, praticamente igual $(1,4 \%)$ a de Morais et al. (2002) na temperatura de $5^{\circ} \mathrm{C}$, é importante ressaltar que o tempo total de armazenamento (30 dias), diferiu de ambos os autores sendo o dobro do utilizado por Menezes et al. (1992) e cinco dias a mais do experimento de Morais et al. (2002). A perda de água pode ser uma das principais causas de deterioração, uma vez que não resulta apenas em perdas diretas quantitativas, mas também perdas na aparência, firmeza e qualidade nutricional (Kader, 1986).

Nesses clones, de acordo com a Figura 1B, nota-se que até o $10^{\circ}$ dia de armazenamento não houve diferença com relação à aparência. Em seguida, os pedúnculos do clone CCP 76 começaram a apresentar aspecto inferior ao clone END 183, com uma vida útil de 18 dias, provavelmente decorrente do teor um pouco mais elevado de antocianinas. Os pedúnculos do clone END 183 tiveram comportamento linear, chegando a aproximadamente 28 dias de vida útil. A 

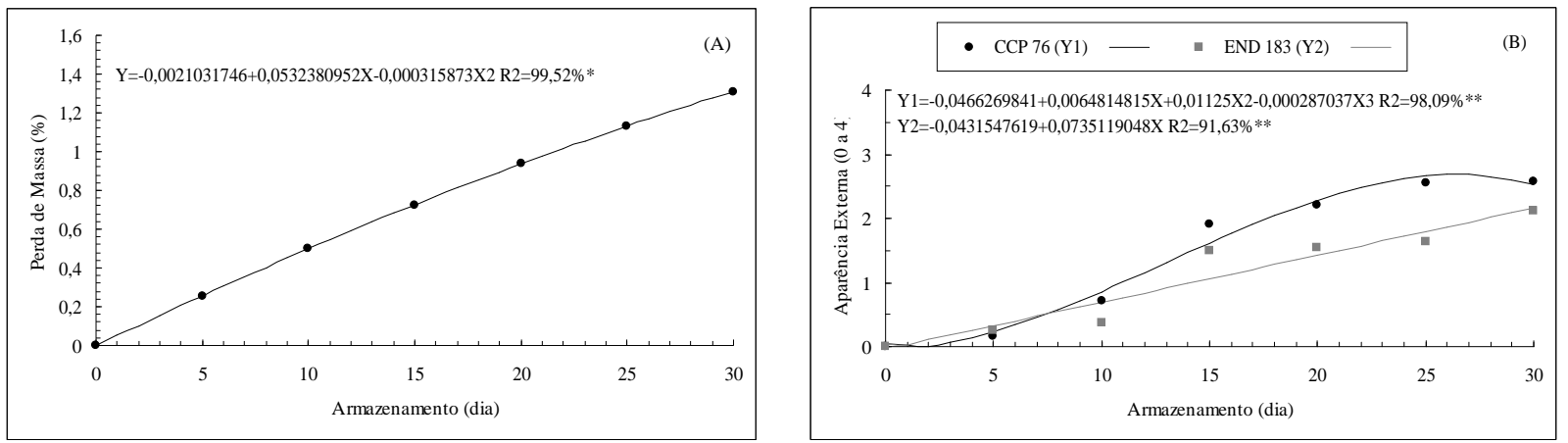

Figura 1 - Perda de massa (A) e aparência externa (B) dos pedúnculos de clones de cajueiro anão precoce, CCP 76 e END 183, armazenados sob atmosfera modificada a $3,4 \pm 0,6^{\circ} \mathrm{C}$ e $85 \pm 11 \%$ de U.R.

redução da temperatura, de $5^{\circ} \mathrm{C}$ utilizada por Menezes et al. (1992), Figueiredo (2000) e Morais et al. (2002) para $3^{\circ} \mathrm{C}$, resultou em maior tempo de conservação, principalmente para o clone END 183.

Para a variável coloração, a luminosidade e a cromaticidade apresentaram resultados estáveis do início ao final do experimento, enquanto o ângulo Hue, apresentou tendência de aumento, indicando amarelecimento (Figura 2A).

Para a variável firmeza, ocorreu uma diminuição de $22 \%$ ao longo do experimento (Figura 2B), influenciando a qualidade dos pedúnculos. Essa diminuição é de interesse econômico, sendo o clone CCP $76(5,11 \mathrm{~N})$ mais prejudicado que o END $183(5,5 \mathrm{~N})$, o que demonstra sua maior suscetibilidade ao armazenamento na temperatura de $3^{\circ} \mathrm{C}$ e $85 \%$ de umidade.

As variáveis SST e AST apresentaram diferença estatística tanto em relação ao tempo como entre clones, com o CCP 76 apresentando valores, para ambas as variáveis, superiores ao END 183. Com relação ao tempo, houve uma ligeira queda, ficando inferior a $10 \%$ ao final desse experimento para os AST (CCP 76), ao longo do período de armazenamento (Figura 3A). Valores próximos a 10\% também foram encontrados por Figueiredo (2000). Mesmo com essa queda, nenhum sinal de senescência que viesse a interferir na qualidade dos pedúnculos para o consumo in natura, foi detectado em ambos os experimentos.

Para a ATT, os clones apresentaram valores no início do experimento próximos de $0,22 \%$, finalizando com ligeira redução (Figura 3B). Ao contrário, o pH e a relação SST/ ATT (Figura 4A e B) apresentaram um leve aumento, ficando o CCP 76 sempre com valores maiores que o END 183 ao final dos 30 dias de armazenamento. De acordo com Kays (1991), uma vez que a concentração de ácidos orgânicos totais tende a declinar após a colheita, o pH sofre, por consequência, uma elevação.
Os dois clones estudados apresentaram redução para a variável ácido ascórbico, com o CCP 76 mantendo valores inferiores e diminuição de $67 \%$, se comparado com o início do experimento (Figura 5A). De acordo com Butt (1980), esse decréscimo (vitamina C) é atribuído à atuação, principalmente, da enzima ácido ascórbico oxidase.

Em trabalho realizado por Figueiredo (2000) com o CCP 76, a redução no teor de ácido ascórbico foi muito pequena até os 15 dias de armazenamento $\left(5^{\circ} \mathrm{C}\right)$, acentuandose a partir dessa data e atingindo teor final $28 \%$ mais baixo que o inicial. Ao comparar o presente trabalho com o realizado por Moura et al. (2004), também com o CCP 76 armazenado na temperatura de $5^{\circ} \mathrm{C}$ por 21 dias, pode-se constatar que não ocorreu diferença na porcentagem de queda entre os ensaios $\left(3^{\circ} \mathrm{C}\right.$ por 30 dias e $5^{\circ} \mathrm{C}$ durante 21 dias de armazenamento); em relação ao END 183 aqui avaliado na temperatura de $3^{\circ} \mathrm{C}$, a queda foi superior quando comparado com $5^{\circ} \mathrm{C}$ no trabalho de Moura et al. (2004). O tempo de armazenamento foi fundamental para a perda maior na temperatura mais baixa.

Para a variável antocianinas totais, o clone CCP 76 perdeu aproximadamente $50 \%$, do conteúdo inicial, enquanto o END 183, perdeu $58 \%$ (Figura 5B). A diminuição da temperatura nos clones alaranjados não surtiu efeito no que se refere à redução nas perdas desse pigmento, se comparado ao trabalho de Moura et al. (2004), que estudou o clone CCP 76 de cajueiro anão armazenado na temperatura de $5{ }^{\circ} \mathrm{C}$, pois em ambos os ensaios $\left(5^{\circ}\right.$ e $\left.3^{\circ} \mathrm{C}\right)$, a perda foi de $50 \%$. A coloração vermelha forte é importante fator de qualidade em frutos e seus produtos, sendo altamente complexo e afetado pelo conteúdo total de antocianinas, estando sujeito às influências genéticas e ambientais, tais como pH e temperatura (Chitarra \& Chitarra, 2005).

Nas três frações fenólicas (dímeras, oligoméricas e poliméricas) analisadas, ocorreram diminuições nos teores durante o armazenamento, sendo que o clone CCP 76 

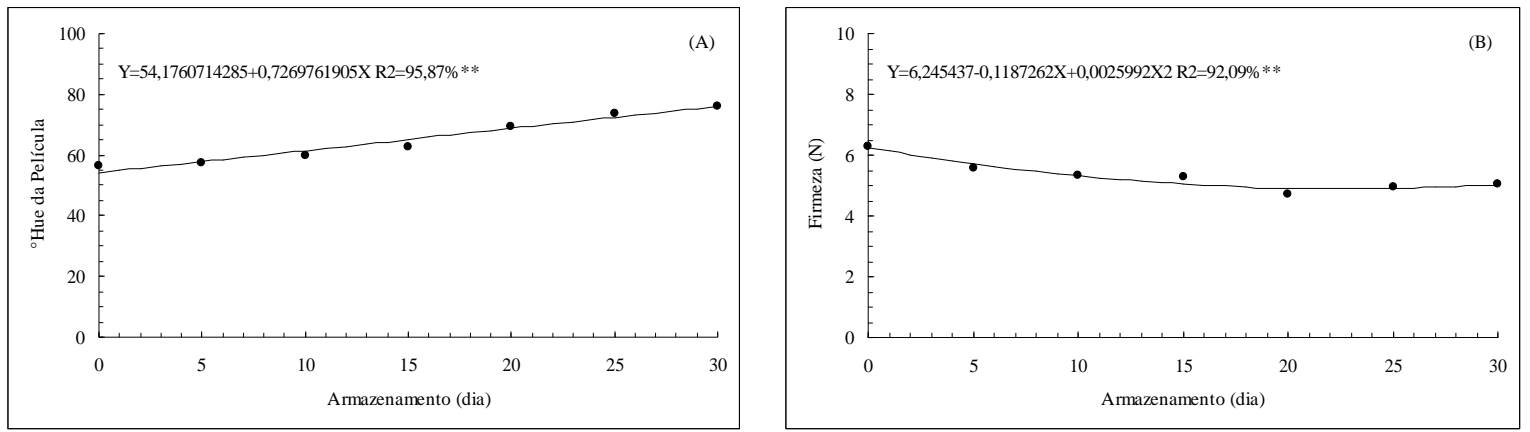

Figura 2 - Ângulo Hue da película (A) e firmeza (B) dos pedúnculos de clones de cajueiro anão precoce, CCP 76 e END 183 , armazenados sob atmosfera modificada a $3,4 \pm 0,6^{\circ} \mathrm{C}$ e $85 \pm 11 \%$ de U.R.
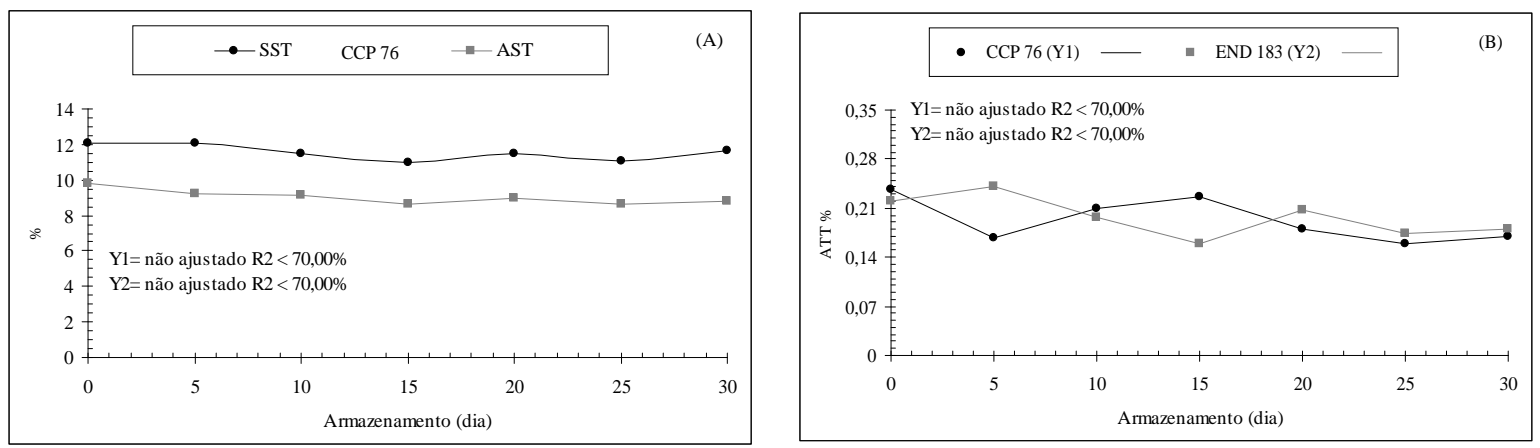

Figura 3 - Teores de sólidos solúveis totais (SST) e açúcares solúveis totais (AST) (A) e acidez total titulável (ATT) (B) de pedúnculos de clones de cajueiro anão precoce, CCP 76 e END 183, armazenados sob atmosfera modificada a 3,4 $\pm 0,6^{\circ} \mathrm{C}$ e $85 \pm 11 \%$ de U.R.
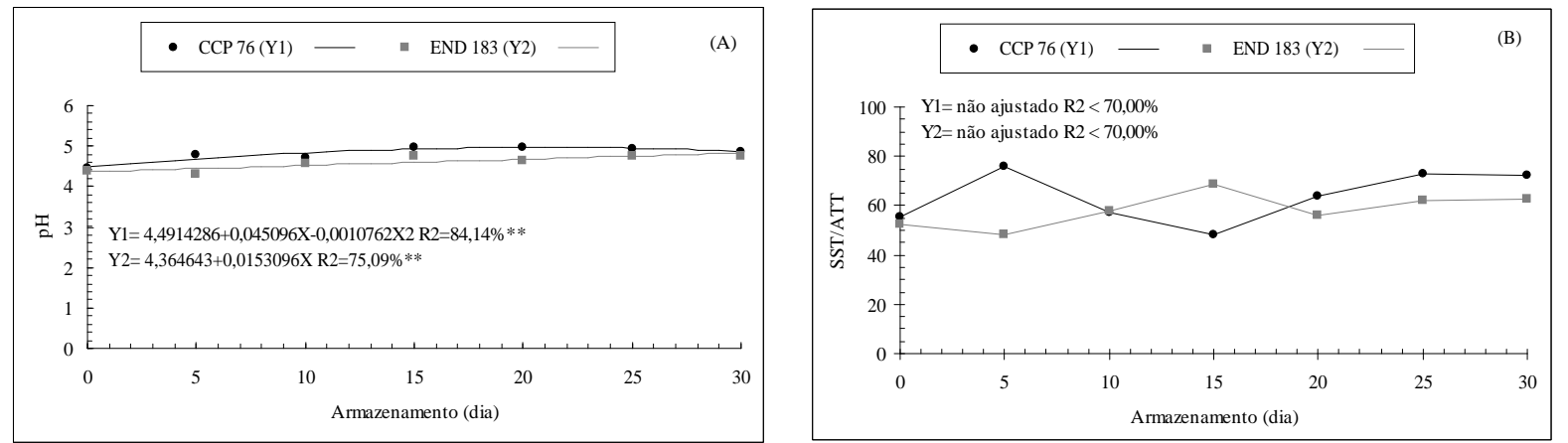

Figura 4 - Teores de pH (A) e SST/ATT (B) de pedúnculos de clones de cajueiro anão precoce, CCP 76 e END 183 , armazenados sob atmosfera modificada a $3,4 \pm 0,6^{\circ} \mathrm{C}$ e $85 \pm 11 \%$ de U.R.

chegou ao final do experimento com uma porcentagem menor para todas as frações (Figura 6A e B), indicando uma menor adstringência desse clone. Esses resultados estão compatíveis com os de Morais et al. (2002), que trabalhando com os clones CCP 76, BRS 189, END 183 e END 189, constataram a mesma tendência de queda em todos os compostos fenólicos durante o período de armazenamento por 25 dias na temperatura de $5^{\circ} \mathrm{C}$. Segundo Menezes \& Alves (1995), isso geralmente ocorre durante o armazenamento refrigerado de pedúnculos do cajueiro, o que também foi observado por Figueiredo (2000) com o clone CCP 76. 

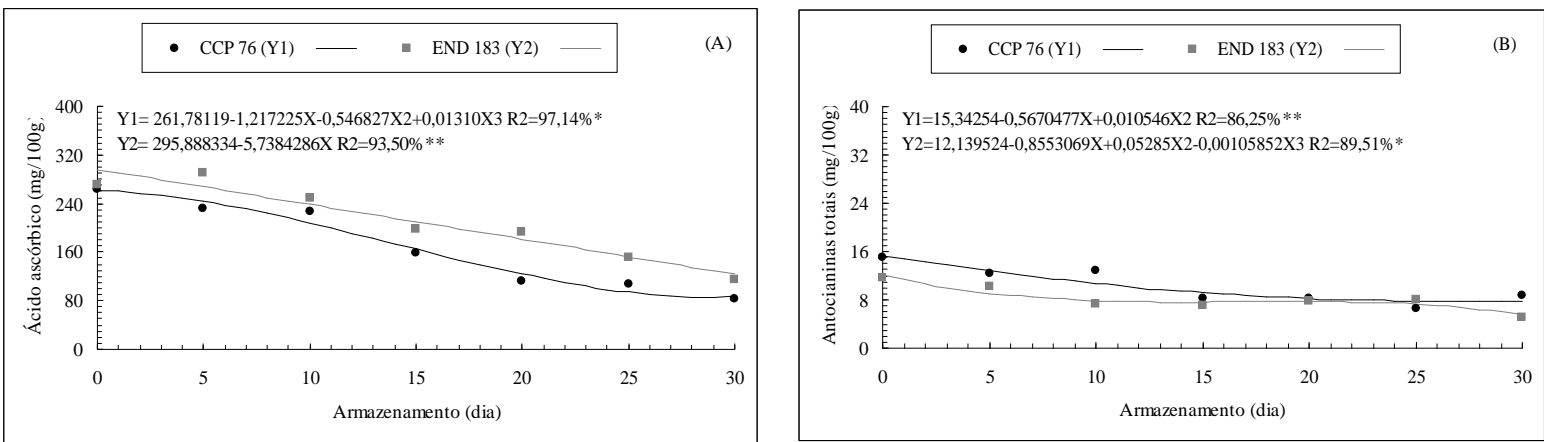

Figura 5 - Ácido ascórbico (A) e antocianinas totais (B) nos pedúnculos de clones de cajueiro anão precoce, CCP 76 e END 183, armazenados sob atmosfera modificada a $3,4 \pm 0,6^{\circ} \mathrm{C}$ e $85 \pm 11 \%$ de U.R.
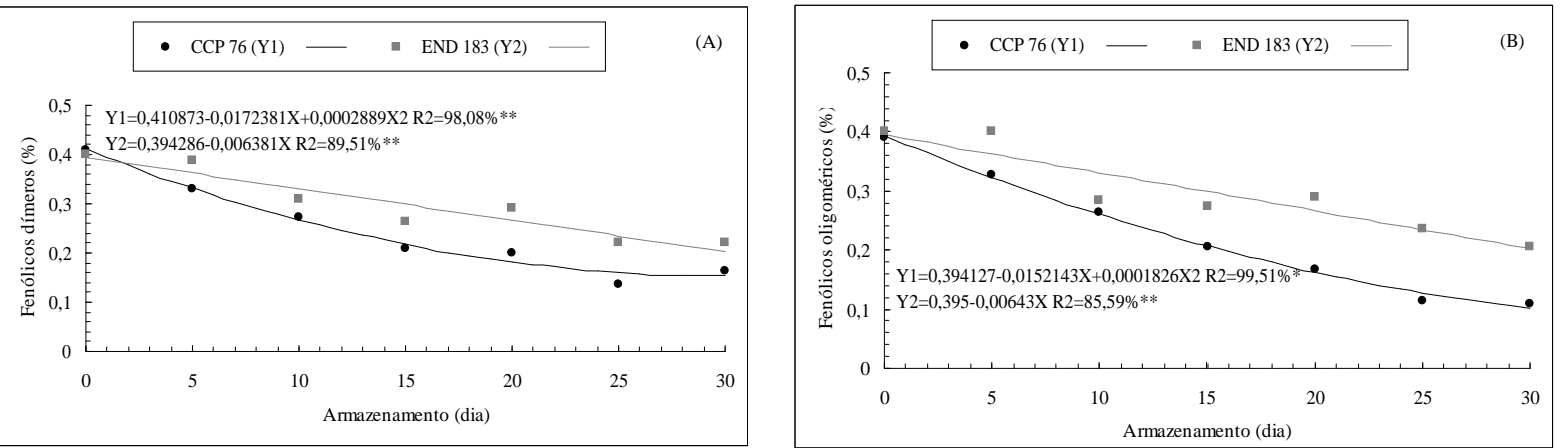

Figura 6 - Teores de fenólicos dímeros (A) e fenólicos oligoméricos (B) em pedúnculos de clones de cajueiro anão precoce, CCP 76 e END 183, armazenados sob atmosfera modificada a $3,4 \pm 0,6^{\circ} \mathrm{C}$ e $85 \pm 11 \%$ de U.R.

\section{CONCLUSÃO}

$\mathrm{O}$ armazenamento de pedúnculos de clones de cajueiro anão precoce na temperatura de $3^{\circ} \mathrm{C}$ teve um grande impacto no aumento da vida útil pós colheita para os pedúnculos do clone END 183 que alcançaram uma vida útil de 28 dias. Já o clone CCP 76 apresenta uma vida útil de 18 dias, ocorrendo para ambos os clones, uma reduzida perda de massa, firmeza e antocianinas totais ao longo do período de armazenamento.

\section{AGRADECIMENTOS}

Ao Conselho Nacional de Desenvolvimento Científico e Tecnológico $(\mathrm{CNPq})$ pelo suporte financeiro por meio do fornecimento de bolsa de pesquisa.

\section{REFERÊNCIAS BIBLIOGRÁFICAS}

ASSOCIATION OF OFFICIAL ANALYTICAL CHEMISTRY. Official methods of analysis of the Association of Official Analytical Chemistry. 11.ed. Washington, 1992. 1115p.
BANZATTO, D.A.; KRONKA, S. do N. Experimentação agrícola. Jaboticabal: Funep, 1992. 247p.

BUTT, V.S. Direct oxidases and related enzimes. In: STUMPF, P.K.; CONN, E.E. The biochemistry of plants: a compreensive treatise. New York: Academic, 1980. v.2, p.81-123.

CHITARRA, M.I.B.; CHITARRA, A.B. Pós-colheita de frutas e hortaliças: fisiologia e manuseio. 2.ed. Lavras: UFLA, 2005. 785p.

FILGUEIRAS, H.A.C.; ALVES, R.E.; MOSCA, J.L.; MENEZES, J.B. Cashew apple for fresh consumption: research on harvest and postharvest technology in Brazil. Acta Horticulturae, Leuven, n.485, p.155-160, 1999.

FIGUEIREDO, R.W. Desenvolvimento, maturação e armazenamento de pedúnculos de cajueiro anão precoce CCP 76 sob influência do cálcio. 2000. 154f. Tese (Doutorado em Ciência dos Alimentos)-Universidade de São Paulo, São Paulo, 2000. 
FRANCIS, F.J. Analysis of anthocyanins. In: MARKAKIS, P. Anthocyanins as food colors. New York: Academic, 1982. p.181-207.

INSTITUTO ADOLFO LUTZ. Normas analíticas, métodos químicos e físicos para análise de alimentos. São Paulo, 1985. v.1, 533p.

KADER, A.A. Biochemical and physiological basis for effects of controlled and modified atmospheres on fruits and vegetables. Food Technology, Chicago, v.40, n.5, p.99-104, 1986.

KAYS, J.S. Postharvest physiology of perishable plant products. New York: AVI, 1991. 543p.

MCGUIRE, R.G. Reporting of objective colour measurement. HortScience, Alexandria, n.27, p.12541255, 1992.

MENEZES, J.B.; ALVES, R.E. Fisiologia e tecnologia póscolheita do pedúnculo do caju. Fortaleza: Embrapa-CNPAT, 1995. 20p. (EMBRAPA-CNPAT. Documentos, 17).

MENEZES, J.B.; CHITARRA, A.B.; CHITARRA, M.I.F. Efeito da temperatura e da atmosfera de armazenamento na conservação de pedúnculo do caju (Anacardium occidentale L.): I., modificações das características físicas. Revista Brasileira de Fruticultura, Cruz das Almas, v.14, n.3, p.75-80, 1992.

MORAIS, A.S.; MAIA, G.A.; FIGUEIREDO, R.W.; ALVES, R.E.; FILGUEIRAS, H.A.C.; MOURA, C.F.H. Armazenamento refrigerado sob atmosfera modificada de pedúnculos de cajueiro anão precoce dos clones CCP 76, END 157, END 183 e END 189. Revista Brasileira de Fruticultura, Jaboticabal, v.24, n.3, p.647-650, 2002.

MOURA, C.F.H.; FIGUEIREDO, R.W.; ALVES, R.E.; ARAÚJO, P.G.L.; SILVA, A.S.; SILVA, E.O. Avaliação respiratória de clones de cajueiro anão precoce (Anacardium occidentale L.) armazenados sob diferentes camadas de PVC. Proceedings of the Interamerican Society for Tropical Horticulture, Miami, v.47, n.1, p.143-145, 2004.

SOUZA, A. R. M. de; BRAZACA, S. G. C.; ARTHUR, V.; OLIVEIRA, A. G. C.; SPOTO, M. H. F.; WALDER, J . M. M. Efeito da radiação gama e do armazenamento na qualidade de pedúnculos de caju (Anacardium occidentale L.). Ciência e Agrotecnologia, Lavras, v. 33, n. 3, p. 848 - 854, maio/jun., 2009.

OLIVEIRA, V.H. Cultivo do cajueiro anão precoce. Sistema de produção. Fortaleza: Embrapa Agroindústria Tropical, 2002. 40p.

REICHER, F.; SIERAKOWSKI, M.R.; CORREA, J.B.C. Determinação espectrofotométrica de taninos pelo reativo fosfotúngstico-fosfomolíbdico. Arquivos de Biologia e Tecnologia, Curitiba, v.24, n.4, p.407-411, 1981.

STROHECKER, R.; HENNING, H.M. Analisis de vitaminas: métodos comprobados. Madrid: Paz Montalvo, 1967. 428p.

YEMN, E.W.; WILLIS, A.J. The estimation of carbohydrate in plant extracts by anthrone. The Biochemical Journal, London, v.57, p.508-514, 1954. 